OPEN ACCESS

Edited by:

Xiangdong Chen,

Union Hospital of Tongji Medical

College of Huazhong University of

Science and Technology, China

Reviewed by:

Andre M. Japiassu,

Oswaldo Cruz Foundation

(Fiocruz), Brazil

Massimo Mapelli,

Centro Cardiologico Monzino

(IRCCS), Italy

*Correspondence:

Matteo Briguglio

matteo.briguglio@grupposandonato.it

Specialty section:

This article was submitted to Intensive Care Medicine and

Anesthesiology,

a section of the journal

Frontiers in Medicine

Received: 13 July 2020 Accepted: 16 February 2021

Published: 25 March 2021

Citation:

Briguglio M, Crespi T, Pino F, Mazzocchi M, Porta M, De Vecchi E, Banfi G and Perazzo P (2021) Clinical Characteristics of Severe COVID-19 Patients Admitted to an Intensive Care Unit in Lombardy During the Italian Pandemic. Front. Med. 8:582896. doi: 10.3389/fmed.2021.582896

\section{Clinical Characteristics of Severe COVID-19 Patients Admitted to an Intensive Care Unit in Lombardy During the Italian Pandemic}

\author{
Matteo Briguglio ${ }^{*}$, Tiziano Crespi ${ }^{2}$, Fabio Pino ${ }^{2}$, Marco Mazzocchi ${ }^{2}$, Mauro Porta ${ }^{3}$, \\ Elena De Vecchi ${ }^{4}$, Giuseppe Banfi ${ }^{1,5}$ and Paolo Perazzo ${ }^{2}$ \\ ${ }^{1}$ IRCCS Orthopedic Institute Galeazzi, Scientific Direction, Milan, Italy, ${ }^{2}$ Intensive Care Unit, IRCCS Orthopedic Institute \\ Galeazzi, Milan, Italy, ${ }^{3}$ Neurology Unit, IRCCS Orthopedic Institute Galeazzi, Milan, Italy, ${ }^{4}$ Laboratory of Clinical Chemistry \\ and Microbiology, IRCCS Orthopedic Institute Galeazzi, Milan, Italy, ${ }^{5}$ Faculty of Medicine and Surgery, Vita-Salute San \\ Raffaele University, Milan, Italy
}

Italy was one of the worst affected European countries during the severe acute respiratory syndrome coronavirus 2 (SARS-CoV-2) pandemic. More than $50 \%$ of Italian cases occurred in the northern region of Lombardy, where the saturation of health services between March and April 2020 forced hospitals to allocate patients according to available resources. Eighteen severe coronavirus disease 2019 (COVID-19) patients were admitted to our hospital needing intensive support. Given the disease fatality, we investigated the patients' characteristics to identify mortality predictors. We counted seven deaths from multiple organ failure, two from septic shock, and two from collapsed lungs. The maximum case fatality was observed in patients who contracted SARS-CoV-2 in hospitals. The fatal outcome was associated with the following baseline characteristics: polymorbidity (OR 2.519, $p=0.048$ ), low body mass index (OR 2.288, $p=0.031$ ), low hemoglobin (OR 3.012, $p=0.046$ ), and antithrombin III (OR 1.172, $p=0.048)$, along with a worsening of $\mathrm{PaO}_{2} / \mathrm{FiO}_{2}$ ratio in the first $72 \mathrm{~h}$ after admission (OR 1.067, $p=0.031$ ). The occurrence of co-infections during hospitalization was associated with a longer need for intensive care $(B=4.511, p=0.001)$. More information is needed to inform intensive care for patients with severe COVID-19, but our findings would certainly contribute to shed some light on this unpredictable and multifaceted disease.

Keywords: SARS-CoV-2, COVID-19, infection, intensive care, intubation, systemic inflammatory response syndrome, sepsis, anesthesia

\section{INTRODUCTION}

The severe acute respiratory syndrome coronavirus 2 (SARS-CoV-2) is a respiratory virus that primarily affects the lungs of the human host and that causes, in susceptible individuals, an unrestrained response of the immune system, respiratory failure, cardiovascular system damage, neuropsychiatric manifestations, and multiple organ injuries (1-4). Since the first outbreak testimony in China at the end of the year 2019, the apparent disease termed coronavirus disease 2019 (COVID-19) had a large-scale spread within a few months. Among the European countries, Italy was the first to confront the worst infection situation, and it has been for many weeks the 
nation most affected, with hundreds of deaths being testified every day. About 60,000 total deaths have been presently confirmed (WHO weekly epidemiological update, 8 December 2020) and over half of all losses having occurred in the northern region of Lombardy, in many respects considered the epicenter of the Italian economic and industrial activity. The number of new cases has been progressively decreasing since May 2020, but at the peak of the emergency scenario in March-April 2020, all the major hospitals in northern Italy were forced to cope with this infection, rapidly corroborating the saturation of the health services (5). Along with the consistent traumatic injuries, patients with severe COVID-19 overflowing from the surrounding clinics were transferred to our hospital in Lombardy (6). In critically ill COVID-19 patients, it is a fact that respiration support saves lives, but reports from the United States, Canada, United Kingdom, and China have observed survival rates ranging from 15 to $97 \%$ (7-11), with the dissimilar signs and biochemical fluctuations possibly depending upon the variety of environmental factors and ethnicity $(12,13)$. Given the need for better characterization of severe COVID-19 patients in our Italian context, the aim of this study is to describe albeit retrospectively the clinical and biochemical characteristics of the COVID-19 patients admitted to the intensive care unit (ICU) of our hospital.

\section{MATERIALS AND METHODS}

Patients admitted to our hospital who resulted positive for SARSCoV-2 have been categorized according to a 4-level classification: level 0 (asymptomatic, the patient should not be hospitalized), level 1 (mild symptoms, pharyngodynia, dry cough, fever), level 2 (moderate symptoms, high fever, persistent dry cough, asthenia, dyspnea, requires non-invasive oxygen support, may require intensive care), and level 3 (severe symptoms, invasive oxygen therapy, requires access to intensive care). This COVID-19 classification, together with the score of the Sequential Organ Failure Assessment (SOFA), the Charlson Comorbidity Index (CCI) (14), and the other clinical data, was extracted from the electronic case report form for all patients admitted to the ICU between March and April 2020. Biochemical parameters comprised routine coagulation parameters (activated partial thromboplastin activity and ratio, prothrombin activity and international normalized ratio, antithrombin III, thrombocyte count), inflammatory markers (fibrinogen, C-reactive protein, procalcitonin), injury factors (amylase, creatine phosphokinase, lactate dehydrogenase, $\gamma$-glutamyl transpeptidase, aspartate aminotransferase, alanine aminotransferase), immune response cells (neutrophils, lymphocytes, monocytes, eosinophils, basophils), proteins (hemoglobin, albumin, creatinine, urea, bilirubin), and minerals (calcium, chloride, phosphorus, magnesium, potassium, sodium). For each parameter, the value at ICU admission, the 72-h mean (the mean in the first 3 days), the 48 -h trend (the difference between the value on day 2 and 1 ), and the 72 -h trend (the difference between the value on day 3 and 1) were calculated. The presence of any infection from bronchial aspirates/bronchoalveolar lavage, blood, or urine was arbitrarily coded 1 point, with the co-occurrence of infections in multiple districts being coded as the sum of points (e.g., the presence of a urinary tract infection $=1$ point, whereas a urinary tract infection plus lung infection $=2$ points).

At baseline, the potential difference between biochemical and respiratory features of patients with hospital-acquired vs. parental-acquired infection was investigated by using paired samples $t$-test for normally distributed continuous values or Mann-Whitney-Wilcoxon (MWW) signed-rank test for skewed continuous values. Skewness was defined by the Shapiro-Wilk test $p<0.05$, with the 72 -h trend of amylase and potassium being the only variables with no normal distribution. Subsequently, the CCI, the body mass index (BMI), the respiratory parameters $\left(\mathrm{PaO}_{2} / \mathrm{FiO}_{2}\right.$ ratio $=\mathrm{P} / \mathrm{F}$; the positive end-expiratory pressure $)$, and all biochemical variables at the 1st day of ICU admission, the 72 -h means, and the trends in the first $72 \mathrm{~h}$ were associated with the binary clinical outcome (survival:death) in the whole cohort through logistic regression. The length of ICU stay combined with the survival in each outcome group was analyzed through separated linear regressions with the occurrence of infections and with the 72-h mean, the 48-h trend, and the 72$\mathrm{h}$ trend of respiratory parameters. All tests were 2-tailed and performed by using IBM SPSS Statistics 22. The raw data used to support the findings of this study are included within the Supplementary Material as a Microsoft Excel worksheet.

\section{RESULTS}

Thirteen males and five females with severe COVID-19 aged $67.77 \pm 9.92$ years old were admitted to the ICU of our hospital in March-April 2020 for intensive care support, and 11 of them were deceased for COVID-19-associated complications. At admission, 17 patients were categorized as level 3 COVID-19 severity and were all subjected to invasive oxygen therapy with either oropharyngeal tube or tracheostomy, whereas one patient was classified as an upper level 2 patient since he maintained respiratory autonomy through the helmet. Most patients suffered from co-existing conditions, with five patients being classified as nosocomial infected patients (see Table 1 for details).

Compared with parental-acquired infections, the hospitalacquired infection patients had higher CCI at admission (5.60 vs. 3.46 , $t$-test $p=0.033)$, lower baseline positive end-expiratory pressure ( 11.00 vs. $14.87 \mathrm{~cm} \mathrm{H}_{2} \mathrm{O}$, $t$-test $p=0.012$ ), lower 72 $\mathrm{h}$ mean of positive end-expiratory pressure $(10.87$ vs. $14.81 \mathrm{~cm}$ $\mathrm{H}_{2} \mathrm{O}$, $t$-test $p=0.014$ ), higher 72 -h mean of thromboplastin activity (35.2 vs. 28.46 , $t$-test $p=0.013$ ), higher 72 -h mean of thromboplastin ratio (1.25 vs. 1.02 , $t$-test $p=0.006)$, lower antithrombin III at 48 -h and 72 -h trends $(-1.00$ vs. $8.77 \%$, $t$-test $p=0.005$ and -5.40 vs. $9.08 \%, t$-test $p=0.021)$, lower baseline fibrinogen ( 441.40 vs. $647.00 \mathrm{mg} / \mathrm{dl}$, $t$-test $p=0.040)$, lower 72 $\mathrm{h}$ trend of amylase ( -34.60 vs. $-11.00 \mathrm{IU} / \mathrm{l}, \mathrm{MWW} p=0.035)$, lower hemoglobin at admission and 72 -h mean (9.50 vs. 11.75 $\mathrm{mg} / \mathrm{dl}, t$-test $p=0.0004$ and 9.26 vs. $11.71 \mathrm{mg} / \mathrm{dl}, t$-test $p=$ $0.0002)$, lower 48 -h trend of albumin $(-0.22 \mathrm{vs} .-0.01 \mathrm{~g} / \mathrm{dl}, t$-test $p=0.046)$, lower potassium at admission and 72-h mean (3.84 vs. $4.44 \mathrm{mmol} / \mathrm{l}$, MWW $p=0.009$ and 3.93 vs. $4.45 \mathrm{mmol} / \mathrm{l}$, $t$-test $p=0.006)$. 
TABLE 1 | Baseline and outcome data of severe COVID-19 patients admitted to our hospital for intensive care support during the Italian pandemic of 2020.

\begin{tabular}{|c|c|}
\hline Descriptors & $\begin{array}{l}\text { Severe COVID-19 patients } \\
\qquad(N=18)\end{array}$ \\
\hline \multicolumn{2}{|l|}{ Demographics } \\
\hline Ethnicity & Caucasian \\
\hline Age (years) & $\begin{array}{c}67.77 \pm 9.92 \\
(43.66 ; 81.10)\end{array}$ \\
\hline Gender (male:female) & $13: 5$ \\
\hline Admission (month) & March-April \\
\hline \multicolumn{2}{|l|}{ Disease severity } \\
\hline SOFA & $6.67 \pm 2.22$ \\
\hline $\mathrm{CCl}$ & $4.06 \pm 1.95$ \\
\hline Hospital-acquired & 5 \\
\hline Parental-acquired & 14 \\
\hline Level 0 & - \\
\hline Level 1 & - \\
\hline Level 2 & 1 \\
\hline Level 3 & 17 \\
\hline \multicolumn{2}{|l|}{ Clinical outcome } \\
\hline ICU stay (days) & $\begin{array}{l}17.17 \pm 7.18 \\
(7.00 ; 35.00)\end{array}$ \\
\hline Discharged $(n)$ & 7 \\
\hline Deceased $(n)$ & 11 \\
\hline \multicolumn{2}{|c|}{$\begin{array}{l}\text { SOFA, Sequential Organ Failure Assessment; CCI, Charlson Comorbidity Index (scores } \\
1-2=\text { mild; scores } 3-4=\text { moderate; scores } \geq 5=\text { severe), COVID-19 level of severity } \\
\text { (level } 0=\text { asymptomatic, the patient should not be hospitalized; level } 1=\text { mild symptoms, } \\
\text { pharyngodynia, dry cough, fever; level } 2=\text { moderate symptoms, high fever, persistent dry } \\
\text { cough, asthenia, dyspnea, requires non-invasive oxygen support, may require intensive } \\
\text { care; level } 3=\text { severe symptoms, invasive oxygen therapy, requires access to intensive } \\
\text { care); ICU, intensive care unit. }\end{array}$} \\
\hline
\end{tabular}

Concerning the survival prediction in the whole cohort, the higher was the baseline BMI (OR 0.437, $p=0.031$ ), antithrombin III (OR 0.853, $p=0.048$ ), and hemoglobin (OR 0.332, $p=0.046$ ), the lower was the risk of death. Conversely, the higher was the polymorbidity represented by a high CCI, the greater was the risk for adverse outcome (OR 2.519, $p=0.048$ ). Those patients who survived vs. those who deceased had these baseline predictors of $30.11 \pm 3.89$ vs. $24.50 \pm 2.31 \mathrm{~kg} / \mathrm{m}^{2}$ for BMI ( $t$-test $\left.p=0.001\right)$, a circulating antithrombin III of $96.71 \pm 14.99$ vs. $72.73 \pm 13.14 \%$ ( $t$-test $p=0.003)$, hemoglobin of $12.03 \pm 1.09$ vs. $10.55 \pm 1.30$ $\mathrm{mg} / \mathrm{dl}$ ( $t$-test $p=0.024)$, and a CCI of $2.71 \pm 1.89$ vs. $4.91 \pm 1.51$ ( $t$-test $p=0.015)$. No other baseline variables were found to be associated with the survival.

Considering the $48-\mathrm{h}$ and $72-\mathrm{h}$ trends of the collected variables, only the negative $72-\mathrm{h}$ trend of $\mathrm{P} / \mathrm{F}$ was found to be predictive of fatal outcome (OR 1.067, $p=0.031$ ). Patients who survived had a 72 -h trend of $\mathrm{P} / \mathrm{F}$ of $+25.34 \pm 25.14$ vs. $-13.23 \pm$ 24.02 for those who deceased ( $t$-test $p=0.005)$. Concerning the length of ICU stay, the non-survivors needed intensive support for $16.00 \pm 5.31$ days, whereas the survivors stayed in the ICU for $19.00 \pm 9.63$ days. No respiratory parameters were found to be associated with the days of ICU stay. Conversely, the occurrence of infections resulted to be predictive of the length of ICU stay in the whole cohort (see Figure 1 for details), with B being 4.656 ( $p=0.0004$; 95\% CI 2.466:6.846).

\section{DISCUSSION}

We have presented the main clinical and biochemical features of 18 patients with severe COVID-19 that were managed in our ICU during the SARS-CoV-2 pandemic in Italy. The demographic descriptors were in line with the literature evidence, being older males the individuals more prone to both being infected and encountering severe consequences of COVID-19 (15). In addition, we found the highest potential for casualty from nosocomial infections, meaning that the infectious crosscontamination affecting already critical patients, for example, surgical patients, could represent an exponential risk for fatal consequences (16).

The baseline clinical descriptor CCI was found to be associated with ICU death. Undeniably, a common denominator of patients with SARS-CoV-2 is known to be the co-existence of multiple conditions, especially cardiovascular diseases (17). The common underlying conditions in the totality of casualties in Italy have been hypertension in $66.8 \%$, type 2 diabetes in $30.0 \%$, and ischemic heart disease in $27.6 \%$ (Italian SARSCoV-2 Surveillance Group, 25 June 2020). Similarly, our cohort comprised hypertension in 11 (61.11\%), type 2 diabetes in $5(27.8 \%)$, and other cardiovascular conditions, such as arrhythmia and vascular diseases, in four cases $(22.2 \%)$. The BMI, antithrombin III, and hemoglobin at admission resulted to be associated with the risk of death. However, the small sample size of our patients limits the generalization of these parameters beyond the context of our study group. Nevertheless, some evidences in the literature are in line with our observations. A high BMI in older adults is known to be protective against adverse events (18), and the human host is known to face a protracted inflammatory status along with a rapid emptying of body reservoirs during any infective complication (19). As a result, a lower BMI in COVID-19 was associated with ICU mortality in a multiethnic population from the United States (7). Furthermore, decreased hemoglobin in non-survivors is suggested to be associated with SARS-CoV-2 interference with iron metabolism and mimicking of hepcidin roles $(20,21)$, the latter being an important regulator of oxygen supply (22). Concerning antithrombin III, low plasma concentrations were found in Chinese patients who deceased for COVID-19associated complications (23). Importantly, the intensive care for our patients comprised equivalent respiration, hydration, nutritional, and pharmacological support with antiviral, antiinflammatory, antiplatelet, and immunosuppressive drugs, but contrariwise covered a different anticoagulant therapy with lowmolecular-weight-heparin (LMWH). The anticoagulant therapy was in fact increased from 4,000 to 6,000 IU of enoxaparin every $12 \mathrm{~h}$ after the first literature sheds evidence highlighting the importance of thromboembolic prevention in COVID-19. Antithrombin III is known to be crucial for heparin activity and $\mathrm{Xa}$ binding, and low circulating levels are associated with a high risk of thromboembolic events. Still, there 


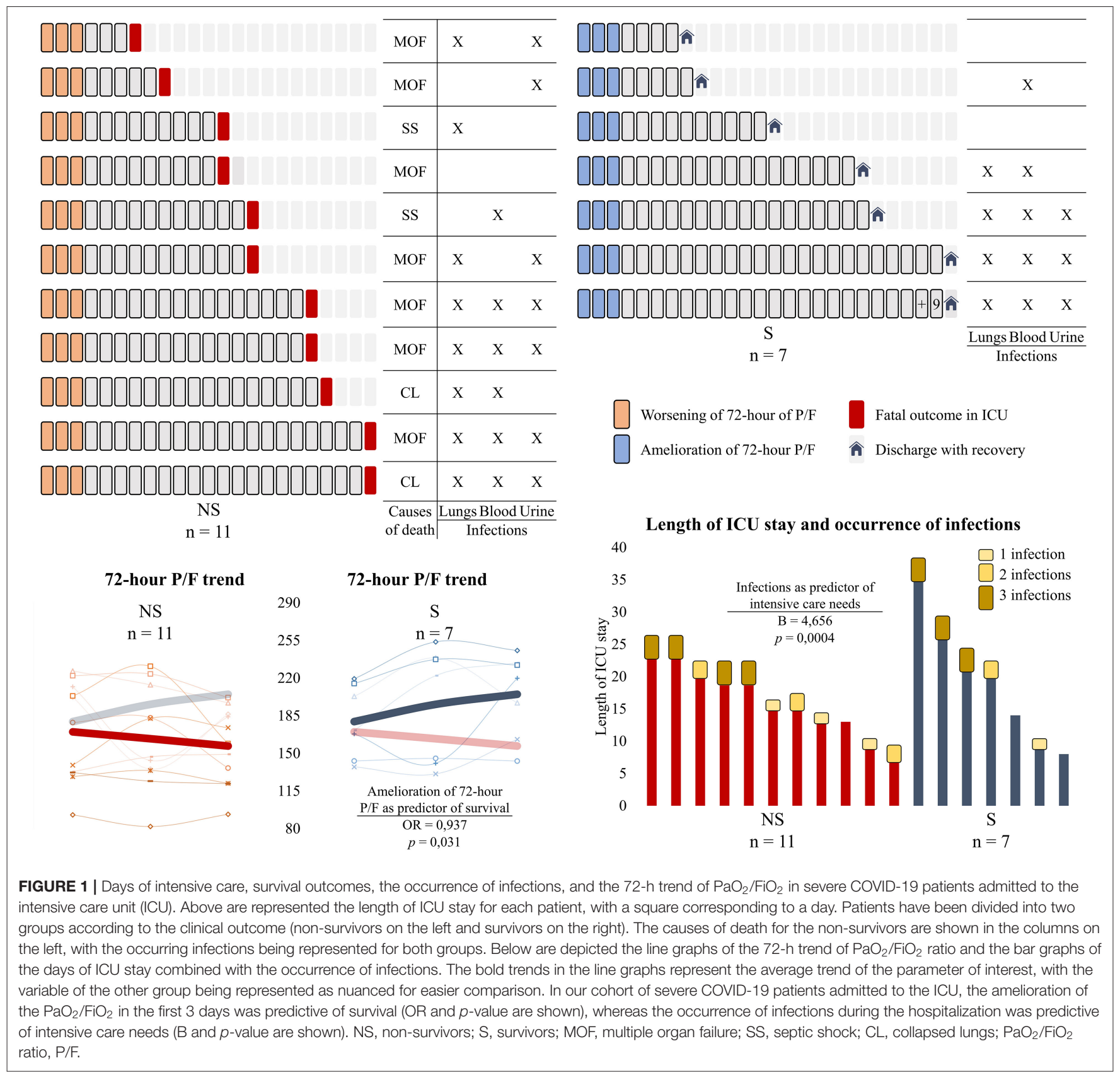

is no consensus about the proper pharmacological therapy for COVID-19, but narrow indications support the use of high pharmacological doses of LMWH and treatment with hyperimmune serums (24-26).

The trend of $\mathrm{P} / \mathrm{F}$ in the first $72 \mathrm{~h}$ was a good predictor of clinical outcome, with the negative trend among the nonsurvivors possibly being ascribed to a late disease stage and therefore to increased alveolar damage. The positive trend in survivors could have also mirrored a good adaptive response to mechanical ventilation and intensive care that hence allowed a discharge with recovery. A significantly better $\mathrm{P} / \mathrm{F}$ ratio at admission was also observed in patients from the United States who survived in the ICU (7), and its early improvement was associated with discharge with recovery in another Italian cohort (27). Elevated markers of liver injury, high C-reactive protein, and low lymphocytes at admission were associated with adverse outcomes in Chinese patients with COVID-19 $(28,29)$, but we found no significant changes of the abovementioned parameters possibly associated with medication concealing. The occurrence and the cumulative value of identified co-infections during hospitalization were positively associated with longer ICU stay in both survivors and non-survivors, and this may be linked with the disruption of host defenses that are no longer able to prevent pathogen migrations $(30,31)$. 
Although our patients were relatively young individuals (mean age $67.77 \pm 9.92$ years), the incidence of mortality of $61.11 \%$ was higher than some previous reports, thus certainly contributing to reducing the ICU stay of non-survivors of 3 days less than the average survivors' length of stay. The great case fatality rate could be due to the co-existence of negative prognostic factors, such as polymorbidity, low BMI, and low hemoglobin. Furthermore, both the respiratory features (worsening of $72-\mathrm{h} \mathrm{P} / \mathrm{F}$ ) and the coagulation abnormalities (low antithrombin III) at admission could be indicative of an advanced stage of the disease. More information will be needed to inform intensive care for these challenging patients and therefore characterize both the unpredictable nature of SARS-CoV-2 and the multifaceted features of COVID-19.

\section{DATA AVAILABILITY STATEMENT}

The datasets presented in this study can be found in online repositories. The names of the repository/repositories and accession number(s) can be found in the article/Supplementary Material.

\section{ETHICS STATEMENT}

Ethical review and approval was not required for the study on human participants in accordance with the local legislation

\section{REFERENCES}

1. Briguglio M, Bona AR, Porta M, Dell'osso B, Pregliasco FE, Banfi G. Disentangling the hypothesis of host dysosmia and SARS-CoV-2: the bait symptom that hides neglected neurophysiological routes. Front Physiol. (2020) 11:671. doi: 10.3389/fphys.2020.00671

2. Haudebourg AF, Perier F, Tuffet S, de Prost N, Razazi K, Mekontso Dessap A, et al. Respiratory mechanics of COVID-19 vs. non-COVID-19 associated acute respiratory distress syndrome. Am J Respir Crit Care Med. (2020) 202:287-90. doi: 10.1164/rccm.202004-1226LE

3. Lai Q, Spoletini G, Bianco G, Graceffa D, Agnes S, Rossi M, et al. SARS-CoV2 and immunosuppression: a double-edged sword. Transpl Infect Dis. (2020) 8:e13404. doi: 10.1111/tid.13404

4. Wijarnpreecha K, Ungprasert P, Panjawatanan P, Harnois DM, Zaver HB, Ahmed A, et al. COVID-19 and liver injury: a meta-analysis. Eur J Gastroenterol Hepatol. (2020). doi: 10.1097/MEG.0000000000001817. [Epub ahead of print].

5. Zagra L, Faraldi M, Pregliasco F, Vinci A, Lombardi G, Ottaiano I, et al. Changes of clinical activities in an orthopaedic institute in North Italy during the spread of COVID-19 pandemic: a seven-week observational analysis. Int Orthop. (2020) 24:1-8. doi: 10.1007/s00264-020-0 4590-1

6. Magro F, Perazzo P, Bottinelli E, Possenti F, Banfi G. Managing a tertiary orthopedic hospital during the COVID-19 epidemic, main challenges and solutions adopted. Int J Environ Res Public Health. (2020) 17:134818. doi: 10.3390/ijerph17134818

7. Auld SC, Caridi-Scheible M, Blum JM, Robichaux C, Kraft C, Jacob JT, et al. ICU and ventilator mortality among critically ill adults with coronavirus disease 2019. Crit Care Med. (2020) 48:e799-804. doi: 10.1097/CCM.0000000000004457

8. Bhatraju PK, Ghassemieh BJ, Nichols M, Kim R, Jerome KR, Nalla AK, et al. Covid-19 in critically ill patients in the seattle region - case series. $N$ Engl J Med. (2020) 382:2012-22. doi: 10.1056/NEJMoa2004500 and institutional requirements. Written informed consent for participation was not required for this study in accordance with the national legislation and the institutional requirements.

\section{AUTHOR CONTRIBUTIONS}

$\mathrm{MB}, \mathrm{TC}, \mathrm{FP}$, and $\mathrm{MM}$ collected the clinical data and managed the database. MB analyzed the data and wrote the first draft of the manuscript. TC, FP, MM, MP, $\mathrm{EDV}, \mathrm{GB}$, and PP revised the first draft and contributed to the manuscript sections. All authors contributed to the manuscript revision and read and approved the submitted version.

\section{ACKNOWLEDGMENTS}

All authors thank all the health workers and volunteers in Italy at the front lines of the fight against SARS-CoV-2.

\section{SUPPLEMENTARY MATERIAL}

The Supplementary Material for this article can be found online at: https://www.frontiersin.org/articles/10.3389/fmed. 2021.582896/full\#supplementary-material

9. Dondorp AM, Hayat M, Aryal D, Beane A, Schultz MJ. Respiratory support in COVID-19 patients, with a focus on resource-limited settings. Am J Trop Med Hyg. (2020) 102:1191-7. doi: 10.4269/ajtmh.20-0283

10. Mitra AR, Fergusson NA, Lloyd-Smith E, Wormsbecker A, Foster D, Karpov A, et al. Baseline characteristics and outcomes of patients with COVID-19 admitted to intensive care units in Vancouver, Canada: a case series. CMAJ. (2020) 192:E694-701. doi: 10.1503/cmaj.200794

11. Zhou F, Yu T, Du R, Fan G, Liu Y, Liu Z, et al. Clinical course and risk factors for mortality of adult inpatients with COVID-19 in Wuhan, China: a retrospective cohort study. Lancet. (2020) 395:105462. doi: 10.1016/S0140-6736(20)30566-3

12. Neher RA, Dyrdak R, Druelle V, Hodcroft EB, Albert J. Potential impact of seasonal forcing on a SARS-CoV-2 pandemic. Swiss Med Wkly. (2020) 150:w20224. doi: 10.4414/smw.2020.20224

13. Vepa A, Bae JP, Ahmed F, Pareek M, Khunti K. COVID-19 and ethnicity: a novel pathophysiological role for inflammation. Diabetes Metab Syndr. (2020) 14:1043-51. doi: 10.1016/j.dsx.2020.06.056

14. Charlson ME, Pompei P, Ales KL, MacKenzie CR. A new method of classifying prognostic comorbidity in longitudinal studies: development and validation. J Chronic Dis. (1987) 40:373-83. doi: 10.1016/0021-9681(87) 90171-8

15. Williamson EJ, Walker AJ, Bhaskaran K, Bacon S, Bates C, Morton CE, et al. OpenSAFELY: factors associated with COVID-19 death in 17 million patients. Nature. (2020) 584:430-6. doi: 10.1038/s41586-020-2521-4

16. Iacobucci G. Covid-19: Doctors sound alarm over hospital transmissions. BMJ. (2020) 369:m2013. doi: 10.1136/bmj.m2013

17. Mehra MR, Desai SS, Kuy S, Henry TD, Patel AN. Cardiovascular disease, drug therapy, and mortality in covid-19. N Engl J Med. (2020) 382:e102. doi: 10.1056/NEJMc2021225

18. Briguglio M, Gianola S, Aguirre MFI, Sirtori P, Perazzo P, Pennestri F, et al. Nutritional support for enhanced recovery programs in orthopedics: future perspectives for implementing clinical practice. Nutr Clin Metabol. (2019) 33:190-8. doi: 10.1016/j.nupar.2019.04.002 
19. Briguglio M, Pregliasco FE, Lombardi G, Perazzo P, Banfi G. The malnutritional status of the host as a virulence factor for new coronavirus SARS-CoV-2. Front Med. (2020) 7:146. doi: 10.3389/fmed.2020.00146

20. Cavezzi A, Troiani E, Corrao S. COVID-19: hemoglobin, iron, and hypoxia beyond inflammation. A narrative review. Clin Pract. (2020) 10:1271. doi: 10.4081/cp.2020.1271

21. Lippi G, Mattiuzzi C. Hemoglobin value may be decreased in patients with severe coronavirus disease 2019. Hematol Transfus Cell Ther. (2020) 42:1167. doi: 10.1016/j.htct.2020.03.001

22. Briguglio M, Hrelia S, Malaguti M, Lombardi G, Riso P, Porrini M, et al. The central role of iron in human nutrition: from folk to contemporary medicine. Nutrients. (2020) 12:61761. doi: 10.3390/nu12061761

23. Tang N, Li D, Wang X, Sun Z. Abnormal coagulation parameters are associated with poor prognosis in patients with novel coronavirus pneumonia. J Thromb Haemost. (2020) 18:844-7. doi: 10.1111/jth.14768

24. Briguglio M, Porta M, Zuffada F, Bona AR, Crespi T, Pino F, et al. SARS-CoV-2 aiming for the heart: a multicenter italian perspective about cardiovascular issues in COVID-19. Front Physiol. (2020) 11:571367. doi: 10.3389/fphys.2020.571367

25. Perazzo P, Giorgino R, Briguglio M, Zuffada M, Accetta R, Mangiavini L, et al. From standard to escalated anticoagulant prophylaxis in fractured older adults with SARS-CoV-2 undergoing accelerated orthopedic surgery. Front Med. (2020) 7:566770. doi: 10.3389/fmed.2020.566770

26. Porfidia A, Pola R. Venous thromboembolism and heparin use in COVID19 patients: juggling between pragmatic choices, suggestions of medical societies and the lack of guidelines. J Thromb Thrombolysis. (2020) 50:6871. doi: 10.1007/s11239-020-02125-4

27. Zangrillo A, Beretta L, Scandroglio AM, Monti G, Fominskiy E, Colombo S, et al. Characteristics, treatment, outcomes and cause of death of invasively ventilated patients with COVID-19 ARDS in Milan, Italy. Crit Care Resusc. (2020). [Epub ahead of print].

28. Kunutsor SK, Laukkanen JA. Markers of liver injury and clinical outcomes in COVID-19 patients: a systematic review and metaanalysis. $J$ Infect. (2020) 82:159-98. doi: 10.1016/j.jinf.2020. 05.045

29. Wang G, Zhang Q, Wu C, Wu F, Yu B, Lv J, et al. Clinical characteristics of adult fevered COVID-19 patients and predictors for developing severe events. Front Med. (2020) 3:324. doi: 10.3389/fmed.2020.00324

30. Santana MF, Pivoto G, Alexandre MAA, Baia-da-Silva DC, Borba M, Val FA, et al. Confirmed Invasive Pulmonary Aspergillosis and COVID-19: the value of postmortem findings to support antemortem management. Rev Soc Bras Med. (2020) 53:e20200401. doi: 10.1590/0037-8682-0401-2020

31. Toombs J, Van den Abbeele K, Democratis J, Mandal AKJ, Missouris CG. Pneumococcal co-infection in Covid-19 patients. J Med Virol. (2020) 93:26278. doi: 10.1002/jmv.26278

Conflict of Interest: The authors declare that the research was conducted in the absence of any commercial or financial relationships that could be construed as a potential conflict of interest.

Copyright (C) 2021 Briguglio, Crespi, Pino, Mazzocchi, Porta, De Vecchi, Banfi and Perazzo. This is an open-access article distributed under the terms of the Creative Commons Attribution License (CC BY). The use, distribution or reproduction in other forums is permitted, provided the original author(s) and the copyright owner(s) are credited and that the original publication in this journal is cited, in accordance with accepted academic practice. No use, distribution or reproduction is permitted which does not comply with these terms. 